\title{
Propuesta para una ampliación del concepto de clínica
}

Es frecuente escuchar durante la visita médica a pacientes hospitalizados, en sesiones clínicas o en los pasillos de los hospitales, conceptos como "lo que manda es la clínica", o "nunca debemos olvidar la clínica". Estos criterios se emiten, ocasionalmente frente al análisis de nuestros pacientes, especialmente cuando ha ocurrido algún error en el diagnóstico, atribuible a un equipo tecnológico moderno o prueba de laboratorio sofisticada, buscando descalificar o desacreditar estos últimos procedimientos. A manera de ejemplo, el tumor que se evidenció en la cirugía o en la sala de Morgagni, y no se detectó tempranamente en el ultrasonido, en el Tomogafía Axial Computada o en la Resonancia Magnética.

Pareciera como si existiera un divorcio, por un lado "la clínica" y por el otro "la alta tecnología". Puestos en términos más precisos, es como si la tecnología moderna utilizada en el diagnóstico, no formara parte de la clínica. Es un error fragmentar el ejercicio del diagnóstico de esta manera.

El Dr Eric Mora Morales, me recordaba el significado de la palabra "clínica", aludiendo "a aquel ejercicio diagnóstico que se realiza a la par de la cama del enfermo".

Es importante estar de acuerdo en que el diagnóstico no es un acto sino un proceso, se inicia con el interrogatorio, el examen físico y procede luego con las pruebas de laboratorio y gabinete. Existen casos clínicos en los que el proceso del diagnóstico cumple su objetivo en las primeras etapas, como en el resfriado común, la insuficiencia cardiaca congestiva o en la fibromialgia, y otros más complejos que demandan de pruebas específicas de laboratorio e imágenes para confirmar o desechar la presunción diagnóstica inicial, como un linfoma con su estirpe celular o una toxoplasmosis del sistema nervioso central.

La clínica nace como respuesta a la necesidad que tiene el ser humano de sistematizar los signos y síntomas de las distintas enfermedades, tratando de comprender su origen, pero sobre todo de aliviar o curar a quien los manifieste. Debe ser muy antigua, pero lo que resulta realmente interesante es el proceso evolutivo que ha seguido a lo largo de la historia, recibiendo un importante impulso para su desarrollo primero con los maestros griegos como Hipócrates en el siglo V (a.C) y luego en la edad media y en el renacimiento, fundamentalmente en los asilos u hosterías, luego hospitales para desposeídos, enfermos y ancianos abandonados en Holanda, Francia e Italia. El referente histórico sobre movimientos de creación de cátedras e institutos clínicos data de los siglos XVII y XVIII en toda Europa, en donde "la enfermedad se presenta al observador de acuerdo con síntomas y signos. Los unos y los otros se distinguen por su valor semántico, así como por su morfología" ${ }^{1}$.

En esa etapa, la interacción entre el clínico y el enfermo era directa, por lo que se quiere entender que eran las habilidades del explorador, su inteligencia, sus destrezas motoras y sensitivas y unos pocos instrumentos, con los que se obtenían los resultados finales para la elaboración del diagnóstico "a la par del lecho del enfermo".

Esta condición se mantuvo casi inalterable hasta después de la segunda guerra mundial, cambio relacionado con el vertiginoso desarrollo tecnológico de la segunda mitad del siglo pasado.

El desarrollo tecnológico propició una mayor sensibilidad y especificidad en el diagnóstico, dejando a su paso una interminable gama de nuevas enfermedades, únicamente identificables a expensas de equipos y pruebas de laboratorio sofisticados. La hepatitis crónica persistente por virus B ó C es exclusivamente diagnosticada por ELISA, RIA ó PCR y el rol del médico se circunscribe a sospecharla, así como a solicitar e interpretar los resultados de los exámenes.

Es decir que existen patologías que actualmente dependen para su diagnóstico preciso más de la tecnología de avanzada que de los síntomas y signos del paciente. Hemos cambiado en algunos casos, el control del médico de todo el proceso, por la sensibilidad y la especificidad en el diagnóstico. El desarrollo tecnológico creó su propia necesidad. Un portador sano del virus de la inmunodeficiencia humana únicamente será diagnosticado por medio de dos Elisas y un Western Blott.

Cuando el médico afirma la supremacía de la clínica, lo hace pensado en aquel componente sobre el cual él tiene absoluto dominio: el inter rogatorio y el exámen físico, incorporando paulatinamente como únicos instrumentos el estetoscopio, el otoscopio y el oftalmoscopio y, quizás aquellos para la exploración neurológica básica.

Algunos más permisivos podrían incluir dentro de este concepto al electrocardiograma y los rayos X, así como algunos exámenes de rutina del laboratorio. Pareciera como si todo lo que sigue en el estudio del paciente deja de ser parte de la 
clínica. Quizás nos parezca que es clínica aquello que permite al médico realizar un ejercicio mental de diagnóstico con los pocos elementos con que cuenta y la satisfacción de sentirse útil se pierde, cuando una máquina o unos reactivos le resuelven el problema. Obviamente hay una crisis de adaptación a las nuevas condiciones en las que la máquina tiende a desplazar al hombre y este se resiste.

Pareciera que el equilibrio está en el medio. Algunas técnicas de la historia clínica, como un buen interrogatorio y una apropiada auscultación cardiopulmonar son imperativas, pero es innegable la ayuda del ecocardiograma y la arteriografía. Quizás lo mejor que podemos decir de las tecnologías pretéritas, presentes y futuras, es que son complementarias.

Pensar por ejemplo que colocar inteligentemente el estetoscopio en la pared torácica del enfermo es hacer clínica, pero aplicar un ultrasonido a la pared abdominal de una embarazada no lo es, significa un divorcio inconveniente de criterios entre lo que se entiende por clínica y lo que se cataloga como alta tecnología. Tan tecnología es el estetoscopio, que por cierto pasó por diversas etapas de su desarrollo desde Laennec (monoaural, flexible y moderno), como tecnología será todo aquello relacionado con los instrumentos de alta resolución que nos permiten ver e interpretar imágenes.

No podemos obviar que algunos procedimientos de los albores de la clínica han desaparecido y otros seguirán perdiéndose, como la aplicación directa del oído del explorador a la espalda del enfermo, conforme nuevas herramientas más eficientes y eficaces de la clínica moderna los vayan desplazando.

No se entienda, porque no es lo que se está diciendo, que se puede eliminar del ejercicio diagnóstico esa primera etapa del interrogatorio y del examen físico, ya que sigue siendo la piedra fundamental en todo el proceso; lo que se está tratando de neutralizar es el concepto en el que se hipertrofia la importancia de esa primera etapa sobre la etapa más tecnológica en el proceso diagnóstico, sin tomar en consideración el tipo de paciente y la enfermedad de que se trate. El abordaje actual del enfermo, o al menos de algunos enfermos, es en equipo, buscando la participación de distintas disciplinas en el ejercicio diagnóstico y terapéutico, necesariamente incorporando con todos sus derechos a los expertos de la nueva tecnología, con sus virtudes y limitaciones.
El ejercicio diagnóstico es un proceso que se compone de etapas, en las cuales el explorador utiliza procedimientos de observación desde muy simples hasta altamente tecnificados. Todos estos procedimientos y los instrumentos y aparatos de tercera y cuarta generación, deberían constituir lo que conocemos como clínica y sobre algunos de ellos el médico tiene mayor control o dominio que sobre otros que se realizan a distancia del lecho del enfermo, pero que luego tienen que ser interpretados con el resto de la información recogida. Esta visión permite una extensión y actualización del concepto de "clínica" que se ha venido utilizando, para relacionarla mejor con el estado del arte del proceso de diagnóstico. Los procedimientos, instrumentos y equipo para el diagnóstico son perecederos y dinámicos por cuanto pueden ser y han sido desplazados por obsoletos por otros más eficientes y eficaces.

Finalmente continúa siendo invaluable la perspicacia, la astucia y creatividad del médico, ya que la aplicación de la vieja y nueva tecnología es plástica, en tanto que varía de acuerdo a la patología que presente el paciente, así como de otras variables más de carácter social y económico, de donde la participación de este profesional sigue siendo imprescindible.

\section{Ignacio Salom-Echeverría \\ Coordinador Clínica VIH \\ Hospital México}

\section{Referencias}

1. Michel Foucault. El nacimiento de la clínica Siglo XXI editores. 12 edición, 1987; pg131. 